\title{
Position Statement of the Brazilian Society of Sports Medicine: Physical Activity and Health in Children and Adolescents
}

\author{
José Kawazoe Lazzoli, Antonio Claudio Lucas da Nóbrega, Tales de Carvalho, \\ Marcos Aurélio Brazão de Oliveira, José Antônio Caldas Teixeira, Marcelo Bichels Leitão, \\ Neiva Leite, Flavia Meyer, Felix Albuquerque Drummond, Marcelo Salazar da Veiga Pessoa, \\ Luciano Rezende, Eduardo Henrique De Rose, Sergio Toledo Barbosa, João Ricardo Turra Magni, \\ Ricardo Munir Nahas, Glaycon Michels and Victor Matsudo
}

\section{INTRODUCTION}

In adults, an active lifestyle is associated to a reduction in the incidence of many chronic diseases, and a reduction in cardiovascular and all-cause mortality. In children and adolescents, a greater physical activity index contributes to improve lipid and metabolic profiles and to reduce obesity prevalence. Also, a physically active child is more likely to become an active adult. In consequence, from public health and preventive medicine perspectives, to promote physical activity in childhood and adolescence is to establish a solid base to reduction of prevalence of physical inactivity in adult age, contributing to a better quality of life. In this context, we emphasize that physical activity is any movement as a result of a skeletal muscle contraction that increases the energy cost above resting values and not necessarily only sports participation.

This document, written by sports and exercise medicine specialists, is based on scientific concepts and clinical experience, having as objectives: 1) to establish the benefits of physical activity in children and youth; 2) to characterize the parameters of assessment and exercise prescription for health in this age; 3 ) to encourage the recommendation and the practice of physical activity in children and adolescents, even with chronic diseases, as absolute contraindications are rare.

1. This document was approved by the Board of Trustees of the Brazilian Society of Sports Medicine on June $26^{\text {th }} 1998$ in a meeting held in Curitiba, PR, Brazil, during the II South-Brazilian Congress of Sports Medicine

2. Originally published in Revista Brasileira de Medicina do Esporte 1998; 4(4):107-9.

3. This document can be reproduced as long as it is clearly identified as an official position statement of the Brazilian Society of Sports Medicine 1998.

\section{EPIDEMIOLOGICAL ASPECTS}

The aging process is accompanied by a tendency to reduce the average daily energy expenditure in consequence of a diminished physical activity. This happens basically for behavioral and social factors, like the increase of school and/or professional demands. A few factors contribute to a less active lifestyle. Availability of technology, lack of security, and the progressive reduction of free spaces in urban centers (where the major part of the Brazilian children live) reduce the opportunities of leisure and a physically active life, thus facilitating sedentary activities, like: watching television, playing videogames and operating computers.

There is a strong association among physical inactivity, obesity and dyslipidemias, and obese children are more likely to grow as obese adults. In consequence, to promote an active lifestyle in children and adolescents may reduce the incidence of obesity and cardiovascular diseases in adult age. Physical activity may produce other long-term benefits, like those related to the skeletal muscle system. Intense physical activity, mainly involving impact, induces an increase in bone mineral density in adolescence and may prevent the risk of osteoporosis in more advanced ages, principally in postmenopausal women.

\section{EXERCISE PHYSIOLOGY}

The general principles that apply to the body responses and adaptations to exercise are the same for children, adolescents and adults. Nevertheless, there are some particularities of exercise physiology in children that are consequent to the increase of body mass (growth) and the maturation that accelerates during puberty (development).

There is an absolute increase in maximal oxygen uptake $\left(\mathrm{V}_{2 m a x}\right)$ with age, with a more rapid increase in boys than in girls. This increase in $\dot{\mathrm{VO}}_{2 \max }$ is closely related to the 
increase in muscle mass, such that if one considers $\mathrm{VO}_{2 \max }$ corrected by indicators of muscle mass, there is no increase with age in male children and adolescents $\left(\dot{\mathrm{VO}}_{2 \max }\right.$ body mass remains constant), while there is a progressive decrease in female children and adolescents $\left(\dot{\mathrm{VO}}_{2 \max }\right.$ body mass decreases).

Anaerobic power augments with age in a greater proportion than the increases in muscle mass, evidencing an effect of maturation on anaerobic metabolism. Anaerobic power does not differ in prepubertal boys and girls, but increases more rapidly in boys after puberty. Thus, the raise in anaerobic power is a consequence of the increase in muscle mass, and the effect of hormonal maturation on the functional characteristics of the skeletal muscle. Also, lactate production is more developed in adults than in children, a reason why children recover more promptly after high-intensity and short duration exercises, being earlier ready for another bout of exercise. Other characteristic that develops with sexual maturation is the buffering capacity of the muscle acidosis that is more efficient with age, allowing for more intense lactic exercises.

There are some characteristics in thermoregulation in children that must be emphasized. The transfer of heat with the environment is greater in children than in adults, as they have a greater body surface corrected for body mass. Thus, children lose heat in cold environments and gain heat in high temperatures more rapidly than adults, being more prone to thermal complications. Also, children tend to have less thirst than adults, dehydrating and decreasing blood volume more easily, with impairment in physical performance and thermoregulation mechanisms.

\section{PRE-PARTICIPATION EXAMINATION}

From a public health perspective, children and adolescents may participate in low and moderate-intensity activities, recreational and leisure activities, with no need of a formal pre-participation examination. It is important that some basic health conditions - as an adequate nutrition are present to implement physical activity.

When the objective is competitive exercise participation or high-intensity activities, the child must undergo a medical and functional assessment, including a clinical evaluation, body composition assessment, aerobic and anaerobic power tests, among others. The main objective of preparticipation evaluation is to assure a favorable risk/benefit relationship, and one must consider the child objectives, and the facilities and personnel available. The risk of cardiovascular complications in children is extremely low, except for congenital cardiovascular diseases and acute illnesses. The presence of some clinical conditions indicates the need for special recommendations and they must be identified and quantified, like asthma, obesity and type I diabetes mellitus.

The bones of children are under development and growth processes until the end of the second decade. The growth plates are vulnerable to lesions consequent to acute trauma and overuse. Anatomic characteristics that may predispose to lesions must be identified.

\section{PRESCRIPTION}

The main objective of physical activity prescription in children and adolescents is to create the habit and interest for physical activity, and not to train aiming performance. Thus, it must be emphasized the inclusion of physical activity in the day-to-day life and to promote school physical education that encourages life-long physical activity, in a pleasant way, integrating the children and not discriminating the less fit.

Competitive sports participation may offer educational and social benefits because it provides experiences of group activities, permitting the child to face situations of winning and losing. However, the objective for performance, mainly when there is excessive pressure by parents and coaches, may produce undesirable consequences, as aversion to physical activity. For this reason, the recreational component of physical activity must be more important than the competitive component when prescribing physical activity to children. Also important is to offer alternatives to sports participation, to consider the individual interests and the development of different motor abilities, contributing to the development of talents.

A formal program of physical activity should consider at least three components: aerobic, muscular strength and flexibility, varying the emphasis in each one according to the clinical condition and the objectives of the child. When the objective is the aerobic conditioning, prescription must consider the following variables: mode, duration, intensity and frequency, following the general principles of training. The strength training should be performed with moderate loads and a greater number of repetitions, emphasizing the motor learning, as this type of activity contributes to an increase in muscle strength and bone mass. The risk of orthopedic lesions in children performing strength exercises is lower than in children performing contact sports, provided that submaximal leads are used with an adequate professional supervision. In flexibility training, it should involve the main joint movements, and each movement should be performed slowly until the point of mild discomfort and then maintained for 10 to 20 seconds. 


\section{RECOMMENDATIONS}

The implementation of physical activity in children and adolescents must be considered as a priority in our society. Thus, we recommend that:

1) Healthcare professionals must combat physical inactivity in children and adolescents, encouraging regular practice of physical activity in the daily life and/or formally with sports participation, even in the presence of diseases, as absolute contraindications to exercise are rare;

2) The professionals involved with children and adolescents that practice physical activity must emphasize the recreational aspects over the competitive aspects and should avoid participation in extremes of temperature;

3) School physical education must be considered essential and an integral part of the global process of education of children and adolescents;

4) The governments at their different levels, the professional and scientific institutions, and the media must consider physical activity in children and adolescents as a public health question, helping to disseminate this information and to implement programs to oriented practice of physical activity.

\section{RECOMMENDED REFERENCES}

1. American Academy of Pediatrics Committees on Sports Medicine and School Health. Physical fitness and the schools. Pediatrics 1987;80:44950

2. American College of Sports Medicine. Opinion statement on physical fitness in children and youth. Med Sci Sports Exerc 1988;20:422-3.

3. Caspersen CJ, Nixon PA, Durant RH. Physical activity epidemiology applied to children and adolescents. In: Holloszy JO, editor. Exerc Sport Sci Rev 1998;26:341-403.

4. Chan K-M, Micheli LJ, editors. Sports and children. Hong Kong: Williams \& Wilkins, 1998

5. Confederación Panamericana de Medicina del Deporte. Physical activity and health in the children of the Americas/Atividad física y salud en los niños de las Americas. Boletin COPAMEDE 1997;1:3.

6. Fédération Internationale de Médecine Sportive. FIMS Consensus Statement on Organized Sports for Children. In: Chan K-M, Micheli LJ, editors. Sports and Children. Hong Kong: Williams \& Wilkins, 1998.

7. Pate RR. Physical activity in children and adolescents. In: Leon AS, editor. Physical Activity and Cardiovascular Health - a National Consensus. Champaign: Human Kinetics, 1997.

8. Sallis JF, Patrick K. Physical activity guidelines for adolescents: Consensus statement. Ped Exerc Sci 1994;6:302-14.

9. US Department of Health and Human Services. Physical activity and health: a report of the Surgeon General. Atlanta, GA: US Department of Health and Human Services, Centers for Disease Control and Prevention, National Center for Chronic Disease Prevention and Health Promotion, 1996.

10. US National Institutes of Health. Physical activity and cardiovascular health. NIH Consensus Development Panel on Physical Activity and Cardiovascular Health. JAMA 1996;276:241-6. 